\title{
PREDICTING ON-TIME DELIVERIES IN TRUCKING: A MODEL BASED ON THE WORKING CONDITIONS OF DRIVERS
}

\author{
Luis David Berrones-Sanz \\ Universidad Autónoma de la Ciudad de México, Prolongación San Isidro 151, San Lorenzo Tezonco, 09790, \\ Iztapalapa, Ciudad de México, México, luis.berrones@uacm.edu.mx
}

Keywords: truck drivers, lead time, arrival time, freight transportation, logistic regression

Abstract: Over a period of two years, 26.3 thousand road freight shipments were recorded. The records include information about truckload companies, drivers, and the causes of non-compliance and delays in deliveries. Logistic regression based in working conditions as independent variables was used to predict non-compliance deliveries attributed to cargo drivers. Results show that vehicle type, medical coverage and social security, level of stress, work dissatisfaction, and transit time were strongly associated with out-of-time-delays in deliveries. The proposed model is a promising tool to improve the performance of truckload companies and it may motivate to benefit working conditions of truckers.

\section{Introduction}

On-Time Delivery (OTD) is one of the key performance indicators in transportation service companies. Failure to comply with OTDs can lead to breakdowns in supply chains, loss of customers and, in general, high costs for transportation that are assumed both in the short and long term. Consequently, leading companies in the supply chain use data analysis to optimize their operations and prevent disruptions in their processes [1]; however, identifying the causes of deviations and preventing non-compliance in deliveries are an obligated task for companies involved in the transport of goods, since it is a highly competitive market with increasingly narrow profit margins.

In this regard, in the international literature there are studies to predict the arrival time and delays of trucks. Van der Spoel, Amrit, and Van Hillegersberg [2] carried out a review of the literature in which they found 82 investigations related to predictors for arrival time. In this investigation, a classification of the factors found in thirteen categories was made: congestion, weather, speed, distance, type of cargo, type of truck, time of day (week, month, and year), cumulative previous deviation, accidents, road work, traffic signal failures, road condition, and driving style. The authors conclude that congestion, time of day, and accidents are the most frequently mentioned factors and that, in a negative way, they are the ones that most influence travel time. However, it stands out that, despite the relationship with the human factor, no variable refers directly to the working conditions of drivers.

Despite the fact people have a crucial effect in determining a successful supply chain [3], the absence of the working conditions of truck drivers in the prediction models of on-time deliveries appears to be the predominant situation. It is undeniable that drivers are a decisive link in transport chains; and it has been established [4] that some working conditions of drivers lead to emotional exhaustion and, therefore, reduce commitment to the organization, negatively affect the service that drivers provide to the customer and, therefore, cause delays and non-compliance in deliveries on time.

Furthermore, previous studies have indicated that late deliveries are one of the main repercussions of drivers' working conditions in the supply chain [5]. The driving activity subjects workers to risks and demands, derived from the organization and technical division of labour, which implies strenuous work rhythms, intense working hours, market structures and lifestyles that determine the health / illness of drivers and affect their physical and mental health [6,7]. Likewise, these investigations focused on Mexican truck drivers have stated that drivers are in precarious working conditions, do not have social security, are prone to diseases, have high stress levels, are dissatisfied with their work, and are subjected to derived workloads work organization, which include the area where they work, the type of vehicle, the size of the company and the type of relationship they have with it [57].

Then, the questioning arises of how the working conditions of the drivers of the freight transport are related in their performance, specifically, in the deliveries on time. In this way, this study aims to explore the relationship between work and drivers' performance, under the assertion that working conditions can explain out-of-time deliveries. Thus, a case study was carried out in a manufacturing company that seeks to reduce noncompliance in deliveries caused by causes attributed to drivers and, based on the availability of variables that determine their working conditions, the binary logistic regression was used to model and predict truckers' on-time deliveries. 
PREDICTING ON-TIME DELIVERIES IN TRUCKING: A MODEL BASED ON THE WORKING CONDITIONS OF DRIVERS

Luis David Berrones-Sanz

\section{Methodology}

\subsection{Description of variables}

During two years, data of 26,312 shipments were kept track, that of a company which manufactures lightweight construction systems in Mexico. Variables such as the labour relationship (employee or owner-operator), access to social security, age and the results of subjective assessment of stress and the satisfaction of the truck drivers were used to determine the factors that affect the performance in the goods deliveries. The variables considered in the study were determined according to previous studies on working conditions of trucks in Mexico $[6,7]$, and with the availability of information from the company in the case study. Finally, eleven independent variables, which are shown in figures 1 and 2 , were considered.

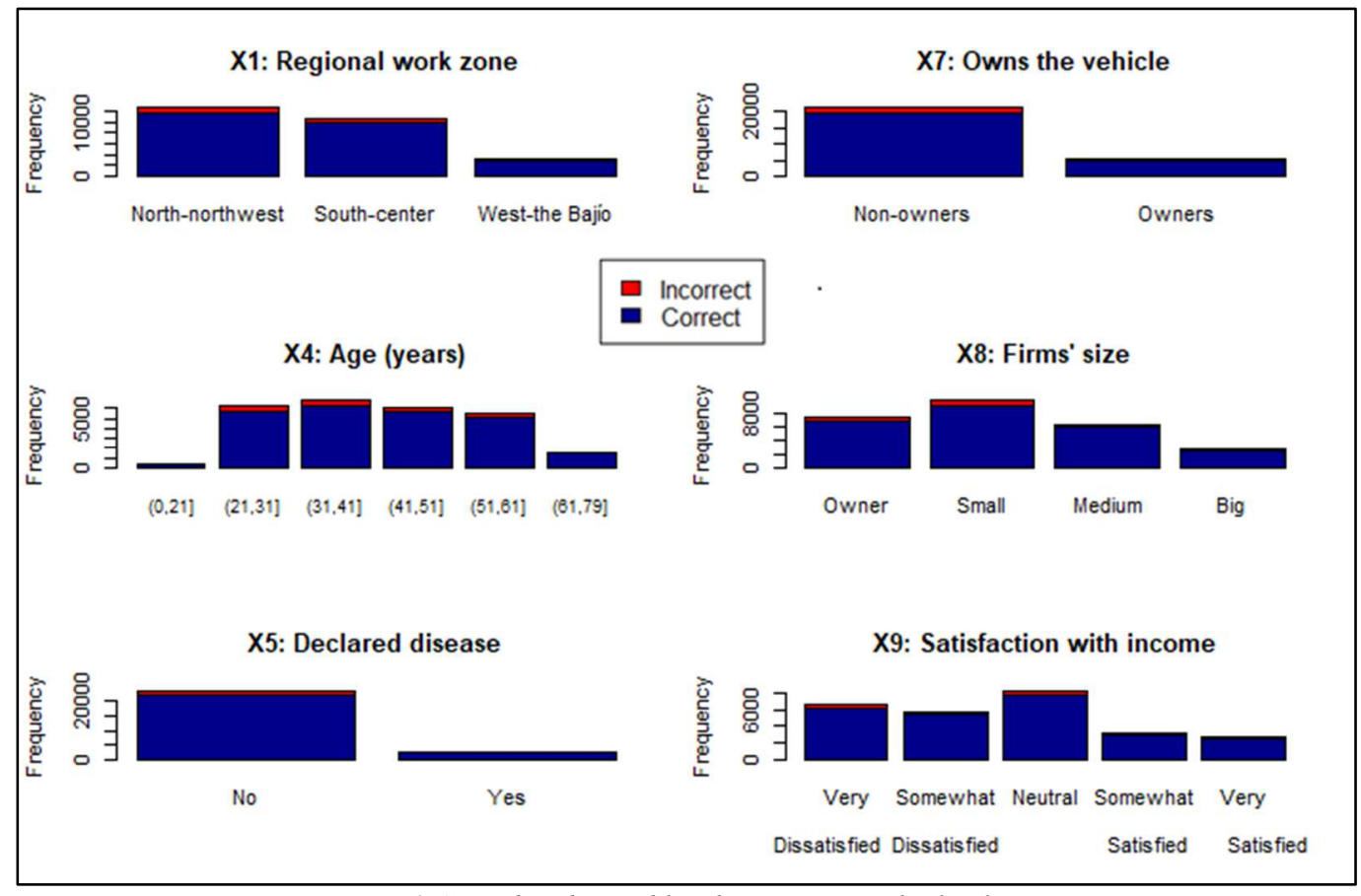

Figure 1 Considered variables that are not in the final equation

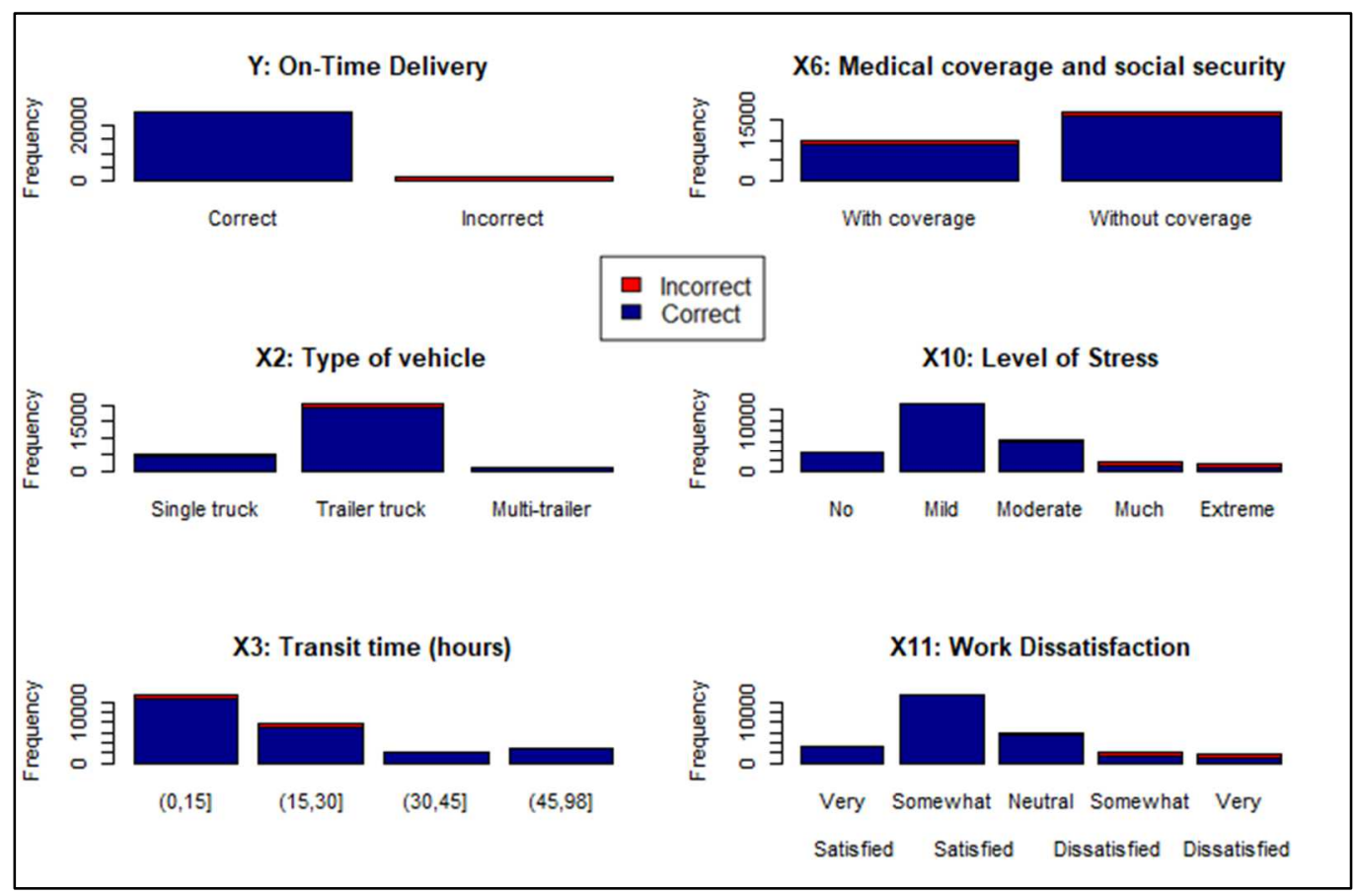

Figure 2 Variables in the equation 
After examining the characteristics of the statistical distribution of the variables involved in the analysis, the bivariate and multivariate relationships, and the analysis of the differences between groups the data were tested in several models of multivariate type. Finally, given that the dependent variable, which was named non-compliance of deliveries $\left(Y_{n c d}\right)$ has the characteristic of being dichotomous (correct or incorrect delivery) a logistic regression approach was found adequate. In this way, to examine the contribution of the independent variables (figures 1 and 2) logistic regression based in working conditions as independent variables was used to predict ontime deliveries attributed to cargo drivers, its significance was verified, and a model of the parsimonious type was constructed.

\subsection{The sending company}

The manufacturing company, which produces approximately $80 \%$ of the total lightweight construction systems that are marketed in Mexico, makes its shipments in heavy vehicles that are loaded in three plants, located in the north, east and west of the country. The different locations manufacture the same products, with the same quality standards, and are shipped, to be distributed throughout the national territory under the same process in three types of vehicles: single trailer 6-axle truck (77.37\%), single unit 3-axle trucks $(18.17 \%)$ and multi-trailer 9-axle trucks $(4.46 \%)$, with a capacity of 19,30 and 56 tons of payload, respectively.

\subsection{Truckload Trucking companies}

The manufacturing company does not have its own vehicle fleet, so all the transportation of the goods is carried out as an outsourced activity. In total, 52 truck companies were used and were classified by the number and type of vehicles available (company size), the location or work area in which they provide the service (north-northwest, south-centre and west-The Bajío), the access to social security, and vehicle ownership (is or not owner-operator).

\subsection{Systematization of data}

The information used in this study was obtained through systematic data recording, from a module named Shipment System -programmed and adapted as a complement to a system of Enterprise Resource Planning (ERP)- and whose main objective is creating indicators for transport services, that the sending company subcontracts. The data were divided into three components: shipment tracking, delivery information, and perception of the driver.

The shipment tracking module records the timetable the driver arrives at the loading point and is available to load, the time it is positioned on the loading platform, the start and end time of the loading process, and the departure time in which drivers start the trip to the final destination. In all these processes, several users use different computers and record the schedules by selecting a checkbox, which cannot be manipulated by the users, and where the schedules are captured in real time. These data are compared with the planned schedules and the fulfilment of time of the truck companies and loading dock personnel is verified.

The delivery information is verified through global positioning systems (if the carrier has the service) or telephone reports made by the drivers. Subsequently, they are verified through the delivery documentation (delivery note), in which the client signs the receipt, reports missing or apparent damage to the materials and establishes the date and time at which the carrier arrived, same that is contrasted with the date in which the delivery was promised.

Finally, to assess the perception of the driver, the documents included three mandatory Likert-type questions, with a scale of one to five, which assessed the level of work stress, dissatisfaction at work and satisfaction with income. Other information about drivers, such as the name, age and if he has social security or medical coverage, was previously entered in the drivers register and during the planning of the shipments.

For the logistic regression, $\mathrm{R}$ software and GLM function (Fitting Generalized Linear Models) were used, and it was used as a dependent variable and it was coded with a one $(Y=1)$ to shipments that were delivered incorrectly, that is, with damages, out of time, or any cause of non-compliance; and with a zero $(\mathrm{Y}=0)$ for the shipments that were delivered in a timely manner (on-timedelivery). This classification includes only the shipments whose causes of non-compliance were attributed to the carriers, and the derivatives for any other reason, such as programming errors or problems in the loading areas are excluded.

Finally, the logistic regression coefficients were used to elaborate an equation that allows calculating the probability of non-compliance in the timely deliveries of truck drivers. In this way, the categories or values taken by the variables that generate both the lowest and the highest probability of non-compliance were identified and, therefore, can be considered protective or risk factors for fulfilment of on-time deliveries.

\section{Result}

Of the 26,312 shipments, almost $14 \%(3,635)$ were registered as inaccurate deliveries that included any cause and not just transportation issues; that is, they were delivered with some missing, wrong materials, damaged or the promised delivery schedule was not met. Of the noncompliances, $1,790(6.81 \%)$ were attributed to causes related to the carriers; represent the event of interest and were coded with $Y=1$. The rest of the shipments were considered correct or on-time and were coded with $\mathrm{Y}=0$.

The shipments frequency classified by correct or incorrect delivery is shown in figures 1 and 2. It can be seen that the highest percentage of incorrect deliveries occurs in small $(2.6 \%)$ and owner-operators $(2.4 \%)$ firms, in the south-centre area $(3.9 \%)$ and in the 6-axle truck type 
Luis David Berrones-Sanz

vehicle $(5.1 \%)$. As for trucks drivers, just over a quarter $(25.5 \%)$ are owners of the vehicle (owner-operator), a fifth (20.6\%) have no social benefits or medical coverage, on average they have an age of $40.7 \pm 12.99$ years, and $8.4 \%$ indicated having a permanent disease; mainly of cardiovascular or chronic degenerative type. In addition, it can be seen that drivers who indicated an extreme level of stress got a higher frequency in inaccurate deliveries, whereas this does not seem to be related to drivers who were very dissatisfied with work or very dissatisfied with income.

\subsection{Logistic regression and the probability model of non-compliance of}

Using $\mathrm{R}$ software, the parameters associated to Logistics Regression were calculated. In this way, Omnibus tests of model coefficients showed the probability of obtaining chi-square statistic $(7,867.237)$, so that there is no effect of the independent variables, taken together, on the dependent variable $(\mathrm{p}<.001)$.

Meanwhile, the Hosmer-Lemeshow test of the goodness of fit suggested the model is a good fit to the data as $\mathrm{p}=0.075$ and the hypothesis null was not rejected (P>.05). Thus, in general, the model has a high specificity $(98.5 \%)$ and an average sensitivity $(65.6 \%)$, so that the model generated through logistic regression offers an overall sample accuracy of $96.3 \%$ in the prediction of the event of out-of-time deliveries.

Table 1 provides variables in the equation in the final step; it contains estimated coefficients, standard error, the Wald statistic ( $\mathrm{z}$ value), statistical significance and the Odds Ratio of the variables involved. Only five variables (figure 2) had statistical significance $(\mathrm{P}<.05)$; these are named: Transit time $\left(X_{3}\right)$, Type of vehicle $\left(X_{2, j}\right)$,), Medical coverage $\left(X_{6}\right)$, Level of stress $\left(X_{10, j}\right)$, and Work dissatisfaction $\left(X_{11, j}\right)$, strongly associated with the out-oftime deliveries.

Table 1 Variables in the Equation

\begin{tabular}{|c|c|c|c|c|c|c|c|}
\hline \multirow{2}{*}{$\begin{array}{c}\text { Variable } \\
X_{i, j}\end{array}$} & \multirow{2}{*}{$\begin{array}{c}\text { Estimate } \\
\left(\boldsymbol{\beta}_{i, j}\right)\end{array}$} & \multirow{2}{*}{ Std. Error } & \multirow{2}{*}{ zvalue } & \multirow{2}{*}{$\operatorname{Pr}(>|z|)$} & \multirow[b]{2}{*}{$\operatorname{Exp}\left(\beta_{i, j}\right)$} & \multicolumn{2}{|c|}{ 95\% C.I. for $\operatorname{EXP}\left(\beta_{i, j}\right)$} \\
\hline & & & & & & Lower & Upper \\
\hline$\beta o$ & -5.42863 & 0.25954 & -20.92 & 0.00 & 0.0044 & 0.0030 & 0.0070 \\
\hline$X_{2,2}$ & 0.43417 & 0.11673 & 3.72 & 0.00 & 1.5437 & 1.2280 & 1.9410 \\
\hline$X_{2,3}$ & 1.18485 & 0.21412 & 5.53 & 0.00 & 3.2702 & 2.1490 & 4.9750 \\
\hline$X_{3, S c}$ & -0.00659 & 0.00263 & -2.51 & 0.01 & 0.9934 & 0.9880 & 0.9990 \\
\hline$X_{6, D i}$ & -0.57919 & 0.09040 & -6.41 & 0.00 & 0.5604 & 0.4690 & 0.6690 \\
\hline$X_{10,2}$ & 0.04556 & 0.25473 & 0.18 & 0.86 & 1.0466 & 0.6350 & 1.7240 \\
\hline$X_{10,3}$ & 1.43868 & 0.24363 & 5.91 & 0.00 & 4.2151 & 2.6150 & 6.7950 \\
\hline$X_{10,4}$ & 4.88311 & 0.23592 & 20.70 & 0.00 & 132.0407 & 83.1550 & 209.6650 \\
\hline$X_{10,5}$ & 5.73594 & 0.23803 & 24.10 & 0.00 & 309.8039 & 194.3030 & 493.9630 \\
\hline$X_{11,2}$ & -1.44191 & 0.12298 & -11.72 & 0.00 & 0.2365 & 0.1860 & 0.3010 \\
\hline$X_{11,3}$ & 0.25132 & 0.11734 & 2.14 & 0.03 & 1.2857 & 1.0220 & 1.6180 \\
\hline$X_{11,4}$ & 1.72793 & 0.13054 & 13.24 & 0.00 & 5.6290 & 4.3580 & 7.2700 \\
\hline$X_{11,5}$ & 2.29704 & 0.13718 & 16.75 & 0.00 & 9.9447 & 7.6000 & 13.0120 \\
\hline
\end{tabular}

Otherwise $=0$

With the coefficients of regression $\beta \mathrm{i}$, which were significant, the model is formed to calculate the probability of non-compliance of deliveries $\left(Y_{n c d}\right)$ it is presented below (1):

$$
\mathrm{P}\left(Y_{n c d}\right)=\left[1+e^{5.42863-\sum_{i=1}^{n} \sum_{j=1}^{m} x_{i, j} \cdot \beta_{i, j}}\right]^{-1}
$$

Table 2 shows the codes for each of its explanatory variables in the final equation. shows the codes for each of its explanatory variables in the final equation.

Table 2 Variables coding

\begin{tabular}{cll}
\hline $\begin{array}{c}\text { Variable } \\
\boldsymbol{X}_{i, j}\end{array}$ & \multicolumn{1}{c}{ Variable name } & \multicolumn{1}{c}{ Code } \\
\hline$\beta_{0}$ & (Intercept) & 1: always \\
$X_{2,2}$ & Single unit 3-axel truck & 1: present, 0: otherwise \\
$X_{2,3}$ & Trailer 6-axel truck & 1: present, 0: otherwise \\
$X_{3, S c}$ & Transit time (hours) & Continuos \\
$X_{6, D i}$ & Medical coverage and social security & 1: present, 0: otherwise \\
$X_{10,2}$ & Mild Stress & 1: present, 0: otherwise \\
$X_{10,3}$ & Moderate Stress & 1: present, 0: otherwise \\
$X_{10,4}$ & Much Stress & 1: present, 0: otherwise \\
$X_{10,5}$ & Extreme Stress & 1: present, 0: otherwise \\
$X_{11,2}$ & Work: Somewhat Satisfied & 1: present, 0: otherwise \\
$X_{11,3}$ & Work: Neither Satisfied nor Dissatisfied & 1: present, 0: otherwise \\
$X_{11,4}$ & Work: Somewhat Dissatisfied & 1: present, 0: otherwise \\
$X_{11,5}$ & Work: Very Dissatisfied & $1:$ present, 0: otherwise \\
\hline \hline
\end{tabular}

Di: Dichotomous variable

Sc: Scale variable 


\section{Discussion}

Some research about drivers has demonstrated that stress affects the performance of workers [4,8]. Thus, it is not surprising that stress has been included as one of the factors in the model and that, to the extent that it increases, the probability of non-compliance of on-time-delivery also increases. However, given that the stress is caused by labour journeys that do not adequately meet the needs of rest, the lack of training to drive their vehicles or other job demands [8]; trying to reduce the level of stress is a complicated task, it already includes practically all the categories of working conditions.

However, it is well-known that an important part of the working conditions of drivers is determined by the characteristics of the vehicle in which they carry out their activities and which has an important influence on their satisfaction [9]. Thus, given that in Mexico 88\% of the vehicle fleet is more than twenty years old [10]; delays are evident in terms of ergonomics, comfort, noise, safety and technological devices that facilitate driving; so the old vehicles not only affect the working conditions and the satisfaction of the drivers, but also put in constant disadvantage the competitiveness of the companies.

In addition to the concerns about the characteristics of vehicles, the satisfaction comprises other dimensions such as job demands, organizational issues, work environment, remuneration, the nature of the tasks performed and even personal situations. In this study, satisfaction was evaluated from two perspectives: 1) subjective work dissatisfaction, which evaluates in a general way the feelings and emotions of the drivers (variable $X_{11, j}$ ); and 2) Satisfaction with income (variable $X_{9, j}$ ) which assesses wellness or pleasure in relation to the money that drivers receive for their work. However, only the subjective dissatisfaction was included in the model as it was significant $(\mathrm{P}<0.01)$, and the variable related to satisfaction with income was excluded $(\mathrm{P}=0.735)$. For these reasons, it is deduced that the drivers are satisfied with their income, although not with other working conditions that are directly related to the inaccuracy of on-time deliveries, so it can be said that the higher levels of work dissatisfaction are related to the risk of out-of-time deliveries.

On the other hand, although the income satisfaction variable was not significant and therefore was not included in the model, it is known that the drivers' income is related to experience and the ability to drive larger vehicles. For example, a driver of vehicles with multi-trailers obtains more income than that of trailer trucks and, in turn, higher income than those of a single unit truck. However, the model shows that vehicles that move more cargo (Multitrailer 9-axle trucks) are more likely to fail on deliveries.

Other studies indicate that the relative odds of death in road accident increases with the size of the vehicle, and it increases up to 3.42 times for heavier vehicles [11]. Although the model does not delve into accidents, vehicle crashes are considered as non-compliance of deliveries, and the results agree on the risk that the size of vehicles (variable $X_{2, j}$ ) imposes on the flow of the transport chain. Given that larger vehicles are more efficient in terms of costs and using the different vehicle configurations depends on the planning and specific needs -such as order size or market conditions- it is not feasible, only to use smaller vehicles. Therefore, training and promotion of road safety must be promoted, so that progressively, drivers have new skills that compensate the dimensions of vehicles and reduce risks in the supply chain.

As for work time, although the proposed model does not directly contemplate the workday, days worked per week or resting time; it incorporates within the variables with statistical significance the programmed transit time, which is part of the work time. Transit time is related with to out-of-time deliveries and calculates its highest probability of default $(97.18 \%)$ in the scheduled deliveries of 36 hours (TOT=36). During that time, a worker drives from the origin to the destination, is present during loading and unloading, he feeds, rests, sleeps and travels about one thousand kilometres. In Mexico, it is common for truck drivers to work by piecework and under a lax regulation of driving hours, which also does not include working hours outside the wheel. Although many hours worked per day can lead bad temper, physical and mental fatigue, excessive drowsiness or anxiety, inattention at work and road fatalities [4], it is known that, a common practice for Mexican drivers is to work up to 76 hours per week and without a proper rest [6]. Consequently, the effects of transit time and long hours of work, not only put the logistics processes at risk through the inaccurate deliveries, but are associated with adverse health effects, such as chronic diseases, or permanent physical and psychological injuries[12].

Also, despite the fact that several studies around the world indicate that driving is among the professions that have the greatest suffering and risk factors associated with their occupation [13], the subjective condition of disease (Variable $X_{5}$ ) did not show statistical significance $(\mathrm{P}=0.276)$ and was not considered for the final model. While in the opposite way, the medical coverage and social security $\left(\right.$ Variable $\left.X_{6}\right)$ had statistical significance $(\mathrm{P}<0.01)$ and are considered for the calculation of probability of noncompliance. However, the percentage of drivers who have medical coverage is high compared to the national total of land transit workers, $63.12 \%$ for the case study versus $42.09 \%$ of the registered drivers in the National Survey of Occupation and Employment [14]. It is important to note that, for this case study, the amount is influenced by the number of companies with more than thirty vehicles, $17.31 \%$ against $2.2 \%$ in the national total [10]; since, on the contrary of the companies of type owner-operator, greater-sized companies provide these benefits to its employees.

Consequently, having the benefit of social security $\left(X_{6}\right)$, represents that the driver is entitled to several privileges, which include access to health services, vacation, bonuses, pension systems, among others; that guarantee certain 
compliance in working conditions. Thus, in spite of the fact that in many cases, as a strategy of evasion of labour taxes, the companies register only minimum wage and not the real remuneration of the driver, and so that in case of temporary or definitive disability, or retirement, they only perceive a minimum part of the usual income; the lack of social security is a factor that participates in the calculation of the highest probability of default on deliveries.

Finally, in comparison with other logistic regression models, and despite the fact that they have different objectives, it can be observed that these have some similar variables. Martínez, Oviedo, and Luna [15] to explain the quality of working life, included variables of job stability, physical load, income and some other stressors. It highlights the similarity of the variables related to stress and physical load which are also considered in the proposed model through variables like $X_{11, j}$ and $X_{3}$. In addition, in the same way as in the proposed model, neither Martínez et al. [15] nor Villar, Delgado, and Barrilao [16] had a statistical significance for the variable income despite the fact that income correlates positively with subjective work conditions; so you can say that income is not as important as other working conditions for the behaviour of workers. Likewise, Villar et al. [16] did not find statistical significance in the region where employees work but indicates that the autonomy of workers influences their satisfaction. Given that in the inaccurate deliveries model the vehicle ownership variable $\left(X_{7, j}\right)$ represents work autonomy, it is possible to consider some contradiction between the two studies. However, the comparison study refers to administrative employees, while the current is based on drivers; and the driving activity already implies a certain autonomy in the work.

For that reason, despite the different objectives of this research, the multi-variant analysis with logistic regression models seems to be a good alternative to explain and predict the relationships between working conditions and workers' behaviour.

\section{Conclusions}

Although the different groups of drivers share risks and demands derived from their labour process, their working conditions vary according to different factors determined by technological, social, cultural, economic and regulatory aspects, including labour laws and traffic regulations; so, some other variables not included in the model could be relevant. However, the five variables used to calculate the probability of non-compliance of deliveries can be considered as dimensions that encompass other factors, and these are related to other working and health conditions, both physical and mental. Thus, for example, the variable $X_{8, j}$ (firms' size) is associated with the longevity of the vehicle fleet, given the larger companies have vehicles with models under six years, while those of the owner-operators are over twenty years.

Briefly, to extrapolate the model to other types of industries, it is necessary to include a greater number of variables (demographic, health, work and organizational, among others), to rule omissions of factors or relevant characteristics, typical of certain industries or products, which may affect the inaccurate deliveries and, therefore, the competitiveness of companies.

In addition, data considered subjective variables. It is recommended that objective methods, as validated tests, are used to measure and reduce the level of stress, job dissatisfaction and the other subjective variables.

However, this study shows the relevance of the working conditions of truckers in terms of how they affect non-compliance in the delivery of goods by road.

The results will be used to create a conceptual model that generalizes, in any type of industry, the effect of labour conditions on inaccurate deliveries. And, finally, despite the limitations of the model, the results show that proposed model is a promising tool to improve the performance of truckload companies and it may motivate to benefit working conditions of cargo drivers.

\section{References}

[1] SANDERS, N.: How to Use Big Data to Drive Your Supply Chain, California Management Review, Vol. 58, $\quad$ No. 3, $\quad$ pp. 26-48, 2016. doi: $10.1525 / \mathrm{cmr} .2016 .58 .3 .26$

[2] VAN DER SPOEL, S., AMRIT, C., VAN HILLEGERSBERG, J.: Predictive analytics for truck arrival time estimation: A field study at a European distribution center, International Journal of Production Research, Vol. 55, No. 17, pp. 5062-5078, 2017. doi:10.1080/00207543.2015.1064183

[3] FAWCETT, S., MAGNAN, G.M., McCARTER, M.W.: The effect of people on the supply chain world: Some overlooked issues, Human Systems Management, Vol. 23, No. 3, pp. 197-208, 2005.

[4] KEMP, E., KOPP, S.W., KEMP, E.: Take This Job and Shove It: Examining the Influence of Role Stressors and Emotional Exhaustion on Organizational Commitment and Identification in Professional Truck Drivers, Journal of Business Logistics, Vol. 34, No. 1, pp. 33-45, 2013. doi:10.1111/jbl.12008

[5] BERRONES, L., GONZÁLEZ, E., LÁMBARRY, F., ROCHA, L.: Study of the effects of working conditions of cargo drivers in the supply chain in Mexico, Direction Y Organizacion, Vol. 71, No. July, pp. 8798. doi:10.37610/dyo.v0i71.580 (Original in Spanish)

[6] BERRONES, L., GONZÁLEZ, E.: State of the art of the work and health conditions of the professional driver, Red de Investigación en Salud en el Trabajo, Vol. 1, No. 2, pp. 21-9, 2018. (Original in Spanish)

[7] BERRONES, L.: Truck drivers in Mexico: a reseach on working conditions and the supply chain, Transporte $y$ Territorio, Vol. 1, No. 17, pp. 251-66, 2017. doi:10.34096/2Frtt.i17.3875 (Original in Spanish)

[8] LÁMBARRY, F., TRUJILLO, M., CUMBRES, C.: El estrés desde una perspectiva administrativa en los conductores de transporte público en la Ciudad de 
México: minibús y metrobús, Estudios Gerenciales, Vol. 32, No. 139, pp. 112-119, 2016. doi:10.1016/j.estger.2016.02.003

[9] ORDAZ, E., MAQUEDA, J.: Condiciones de trabajo en el transporte público por carretera, Medicina y Seguridad del Trabajo, Vol. 60, No. 234, pp. 90-8, 2014. doi:10.4321/S0465-546X2014000100008 (Original in Spanish)

[10] GAF: Basic statistics of federal motor transport 2018, México: Dirección General de Autotransporte Federal (DGAF), 2018.

[11] BERRONES, L.: Injuries, illnesses and accidents of truck drivers in Mexico, Red de Investigación en Salud en el Trabajo, Vol. 2, No. 1, pp. 41-2, 2019. (Original in Spanish)

[12] BEEK, A.: World at work: truck drivers, Occupational \& Environmental Medicine, Vol. 69, No. 4, pp. 291-295, 2012. doi:10.1136/oemed-2011100342

[13] TSE, J., FLIN, R., MEARNS, K.: Bus driver wellbeing review: 50 years of research, Transportation Research Part F: Traffic Psychology and Behaviour,
Vol. 9, $\quad$ No. 2, $\quad$ pp. 89-114, 2006. doi:10.1016/j.trf.2005.10.002

[14] INSTITUTO NACIONAL DE ESTADÍSTICA Y GEOGRAFÍA: Encuesta Nacional de Ocupación y Empleo (ENOE): Población ocupada, Conductores y ayudantes de conductores de maquinaria móvil y medios de transporte, Cuarto trimestre del 2019, [online], Available: https://www.inegi.org.mx/progr amas/enoe/15ymas/ [20 Oct 2020], 2019. (Original in Spanish)

[15] MARTÍNEZ, L., OVIEDO, O., LUNA, C.: Impacto de las condiciones de trabajo en calidad de vida laboral: Caso del sector manufacturero de la Región Caribe colombiana, Dyna, Vol. 82, No. 194, pp. 194203, 2015. (Original in Spanish)

[16] VILLA, E., DELGADO, J., BARRILAO, P.: Job Satisfaction Among Spanish Tax Administration Employees: A Logistic Regression Analysis, Journal of Labor Research, Vol. 36, No. 2, pp. 210-223, 2015.

\section{Review process}

Single-blind peer review process. 